\section{Theoretical \& Applied Science}

p-ISSN: 2308-4944 (print) ｅ-ISSN: 2409-0085 (online)

Year: 2017 Issue: 09 Volume: 53

Published: $30.09 .2017 \quad$ http://T-Science.org
Doctor of Philosophy in Economics,

Senior lecturer of the department

"Regulation of Economics"

Azerbaijan State Economic University,

Baku city, Azerbaijan Republic nauka-xxi@mail.ru

SECTION 31. Economic research, finance,

innovation, risk management.

\title{
THE PROBLEMS AND WAYS OF DIRECTION OF MACHINE- BUILDING COMPLEX OF THE AZERBAIJAN REPUBLIC
}

\begin{abstract}
The problems and ways of the direction of development of the machine-building complex of the Republic of Azerbaijan are studied in the article. The historical features and evolution of the development of the machine-building complex and machine-building enterprises in Azerbaijan are analyzed. The role of the oil industry in the formation and development of the machine-building industry is considered. The directions and places of oil and gas chemical engineering in the economy of Azerbaijan and the development of the oil and gas industry are given. Particularly, the role of machine building in the economy of Azerbaijan in the 70-80s of the 20th century is revealed. The processes of development of the machine-building complex after the restoration of the independence of Azerbaijan with the collapse of the former USSR are considered. The management system and the structural subdivision of the machine-building complex in the current conditions are analyzed. The main indicators for the output of products, including some types of cars and tractors, are given. A number of recommendations and suggestions on the problems and ways of developing the machine-building complex of the Azerbaijan Republic are made and prepared.

Key words: machine-building complex of Azerbaijan, development of machine-building complex of Azerbaijan, problems of development of machine-building complex of Azerbaijan, ways of direction of development of machine-building complex of Azerbaijan, role of machine-building industry in Azerbaijan's economy.

Language: Russian

Citation: Kazymova AK (2017) THE PROBLEMS AND WAYS OF DIRECTION OF MACHINEBUILDING COMPLEX OF THE AZERBAIJAN REPUBLIC. ISJ Theoretical \& Applied Science, 09 (53): $206-$ 211.

Soi: http://s-o-i.org/1.1/TAS-09-53-31 Doi: crossef https://dx.doi.org/10.15863/TAS.2017.09.53.31

\section{ПРОБЛЕМЫ И ПУТИ НАПРАВЛЕНИЯ РАЗВИТИЯ МАШИНОСТРОИТЕЛЬНОГО КОМПЛЕКСА АЗЕРБАЙДЖАНСКОЙ РЕСПУБЛИКИ}

Аннотация: В статье исследованы проблемы и пути направления развития машинострочтельного комплекса Азербайджанской Республики. Анализированы исторические особенности и эволюция развития машиностроительного комплекса и машиностроительных предприятий в Азербайджане. Рассмотрена роль нефтяной промышленности в формировании и развитии машинострочтельной промышленности. Даны направления и места нефтегазохимического машиностроения в экономике Азербайджана и развитие нефтегазовой промышленности. Особо раскрыты роль машиностроения в экономике Азербайджана 70-80 годов ХХ века. Рассмотрены прочессы развития машиностроительного комплекса после восстановления независимости Азербайджана с распадом бывшего СССР. Анализирована система управления и структурное подразделение машиностроительного комплекса в нынешних условиях. Даны основные показатели по выпуску продукиии и в том числе по отдельным видам автомобилей и тракторов. Подготовлен ряд рекомендаций и даны предложения по проблемам и путям направления развития машиностроительного комплекса Азербайджанской Республики.

Ключевые слова: машиностроительный комплекс Азербайджана, развитие машинострочтельного комплекса Азербайджана, проблемы развития машиностроительного комплекса Азербайджана, пути направления развития машиностроительного комплекса Азербайджана, роль машиностроительной промышленности в экономике Азербайджана.
\end{abstract}




\section{Introduction}

После последнего мирового финансового кризиса многим странам мира пришлось провести существенные изменения в приоритетных направлениях деятельности модели экономического развития страны и практичных механизмах деятельности национальной экономики, в работе отдельных секторов экономики страны. Азербайджан, как страна нефтеэкспортер испытывала серьезное глобальное влияние из-за изменений цен на нефть на мировых рынках и углубление негативных последствий финансового кризиса в мире. Сократились уровень валютных поступлений страны, ухудшился платежный баланс и снизился объем валютных запасов. Страна испытывала финансовую нестабильность из-за падения курса национальной валюты и, в результате, закрылся ряд ранее успешно функционирующих коммерческих банков. Остановили свою работу десятки небанковских кредитных организаций, наблюдалась нехватка кредитных ресурсов, и уменьшился объем капитального вложения в различные реальные сектора экономики страны. Исходя из вышеприведенных факторов, правительство Азербайджана разработало и начало исполнять стратегические дорожные карты по перспективному развитию национальной экономики и по его отдельным секторам [1].

\section{Materials and Methods}

Особое место в экономической политике по совершенствованию механизмов национальной экономики отводится развитию ненефтяного сектора национальной экономики с целью уменьшения его зависимости от нефтяного фактора в ближайшей перспективе. Отметим, что одна из перспективных сфер ненефтяного сектора, которая имеет немалый потенциал, а также особенности по конкурентоспособности является машиностроение. История развития машиностроения в Азербайджане тесно связана с историей развития нефтяной промышленности. Начиная с середины XIX века, в Баку уже появились первые нефтяные промышленные промыслы и нефтяные заводы. Для обслуживания этих отраслей необходимо было разного вида стальные изделия и оборудования. Так и появилась первая ремонтная механическая мастерская в городе Баку в 1858 году и, далее интенсифицировалось машиностроительных предприятий развитие Азербайджане Уже в начале XX века только в Баку функционировало 13 машиностроительных заводов и 127 механических и металлоперерабатывающих мастерских, где работало свыше 8 тысяч человек [2]. Однако все эти процессы замедлились с началом Первой Мировой Войны и с приходом к власти большевиков в России. Вскоре, первая Демократическая Республика на востоке Азербайджанская Демократическая Республика была захвачена большевиками и пала (28 апреля 1920). После этого, Азербайджан находился в составе бывшего СССР почти свыше 70-ти лет (1920-1991). Азербайджан для СССР представлялся, как сырьевая база топливных ресурсов. Руководство СССР рассматривала только выделение капитальных вложений на развитие самой нефтедобычи, однако остальные сектора, связанные с нефтедобычей развивались медленно, вовсе были забыты. Так и продолжалось долгие годы. Только, начиная с середины 30-ых годов XX века, в Азербайджане было заложено начало развития сферы машиностроения. Так, к 1935-му году на базе объединений предприятий по ремонту и производству нефтепромыслового оборудования и инструментов был организован Трест «Азнефтемаш», ныне являющийся «Азнефтехиммаш». Данное предприятие с 2001 года имеет статус Открытого Акционерного Общества «Азнефтехиммаш» [3]. Основная деятельность машиностроительного предприятия Азербайджана была связана с изготовлением нефтегазовых оборудований для добычи нефти и газа [4]. В составе СССР бурный период развития машиностроения в Азербайджане приходился на период Великой Отечественной Войны, где только в Баку созданы 10 машиностроительных заводов, которые выпускали оружие, боеприпасы, a после войны эти предприятия занимались производством насосов, электрических двигателей, силовых трансформаторов, многочисленных видов средств автоматизированных и приборов для нефтегазовой промышленности. В период 19701985 годов в Азербайджане произошел серьезный прогресс в расширении деятельности машиностроительного комплекса $[5 ; 6]$. С целью развития материально-технической базы нефтяной промышленности в Азербайджане на побережье Каспийского моря было построено крупное машиностроительное предприятие Завод Глубоководных Оснований. Основная функция данного завода была создание инфраструктуры и необходимых оборудований для добычи нефти в Каспийском шельфе. Наряду с городом Баку, в разных крупных городах и регионах Азербайджана был сформирован потенциал производства и сети предприятий машиностроительного комплекса (гг.Гянджа, Мингячаур, Ширван, Шемаха, Нахчыван и прочие). 


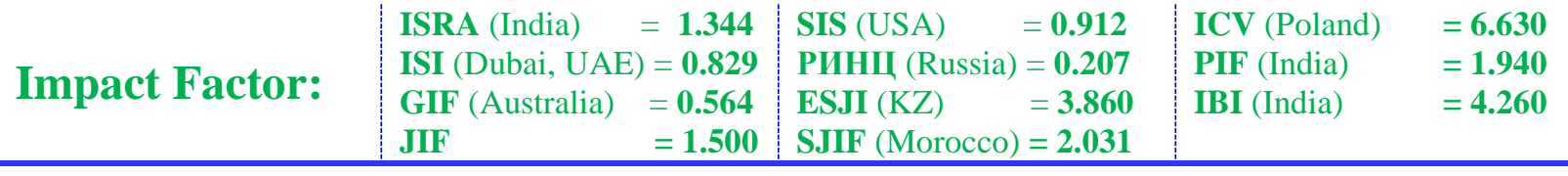

После восстановления независимости в Азербайджане в начале 1990-х годов произошло падение уровня производства во всех предприятиях машиностроительного комплекса. Учитывая этот фактор, началось преобразование в управление машиностроительного комплекса в Азербайджане. С Указом Президента Азербайджанской Республики от 22 марта 2001 года было сформировано ОАО «Азнефтехиммаш», где в его состав было включено 14 дочерних предприятий. На предприятиях ОАО «Азнефтехиммаш» выпускались свыше 130 видов различных продукций, а в целом имеется возможность организации и расширения производства 650 видов различных продукций, оборудований и инвентарей нефтегазового и нефтехимического назначения. Однако возможность и потенциал машиностроительного комплекса в Азербайджане эффективно не используется, предприятия данной отрасли функционируют или работают значительно ниже своих производственных мощностей [7; 8].

На Рисунке 1 дан объем выпуска по основным видам продукции за период 2011-2016 годы.

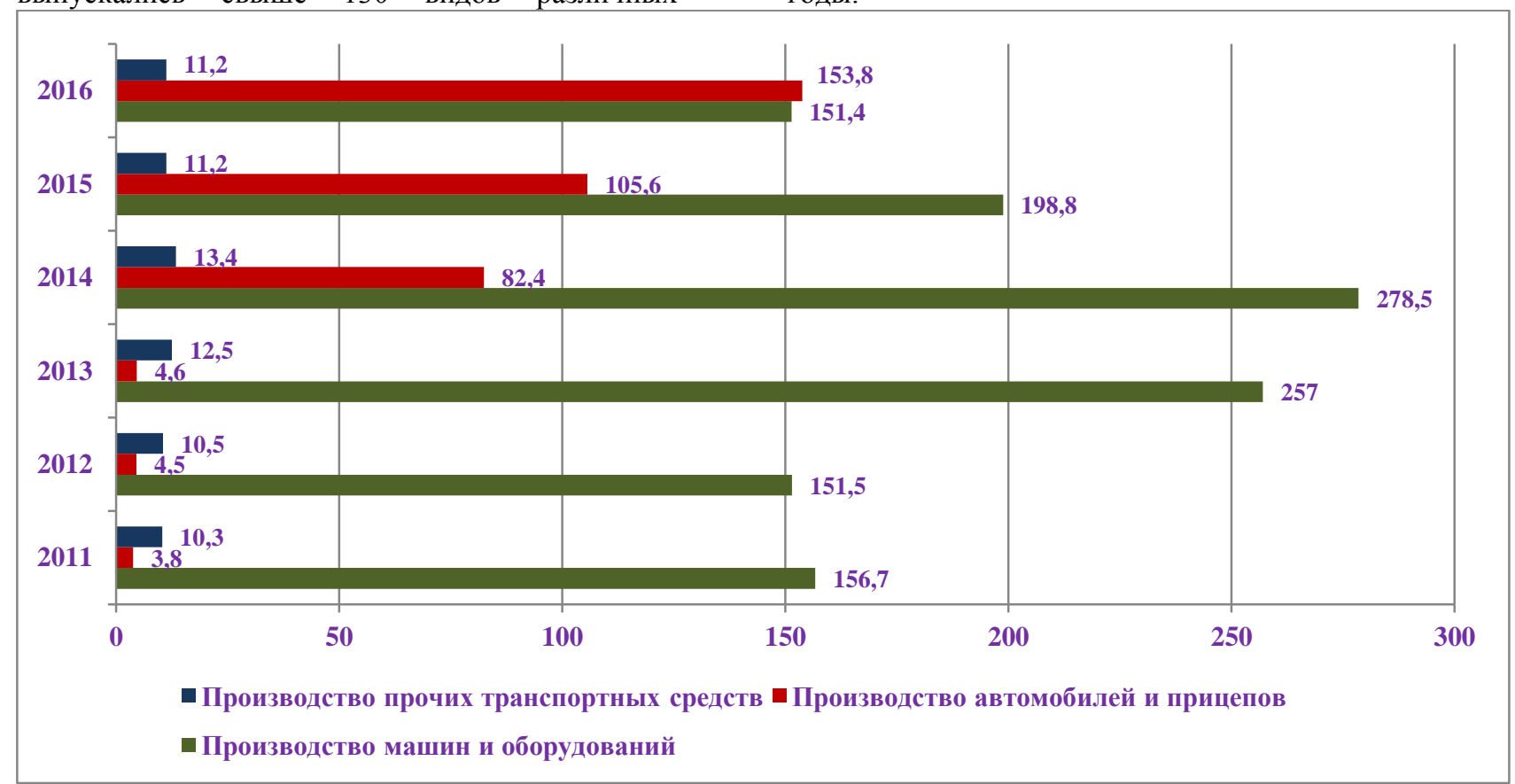

Рисунок 1 - Объем выпуска по основным видам продукции, 2011-2016 годы, млн. манат (подготовлено автором на основе материалов Государственного Статистического Комитета Азербайджанской Республики, http://www.azstat.org).

За период 2011-2016 годы уровень выпуска продукции в машиностроительном комплексе страны не проявил особый рост и функционировал ниже своих возможностей [9; 10]. В целом, машиностроительный комплекс может производить намного крупного объема важное оборудование и продукцию для нефтегазовых и нефтехимических отраслей, а также других сфер машиностроения и тем самым внести серьезный вклад в развитие экономики страны [11].

На Рисунке 2 дано количество предприятий, производящих машины и оборудование в Азербайджане, за 2011-2016 годы. 


\begin{tabular}{|c|c|c|c|c|c|c|}
\hline Impact Factor: & $\begin{array}{l}\text { ISRA (India) } \\
\text { ISI (Dubai, UAE } \\
\text { GIF (Australia) } \\
\text { JIF }\end{array}$ & $\begin{array}{l}=1.344 \\
=0.829 \\
=0.564 \\
=1.500\end{array}$ & $\begin{array}{l}\text { SIS (USA) } \\
\text { PИНЦ (Russia) } \\
\text { ESJI (KZ) } \\
\text { SJIF (Morocco) }\end{array}$ & $\begin{array}{l}=\mathbf{0 . 9 1 2} \\
=\mathbf{0 . 2 0 7} \\
=\mathbf{3 . 8 6 0} \\
=\mathbf{2 . 0 3 1}\end{array}$ & $\begin{array}{l}\text { ICV (Poland) } \\
\text { PIF (India) } \\
\text { IBI (India) }\end{array}$ & $\begin{array}{l}=6.630 \\
=1.940 \\
=4.260\end{array}$ \\
\hline
\end{tabular}

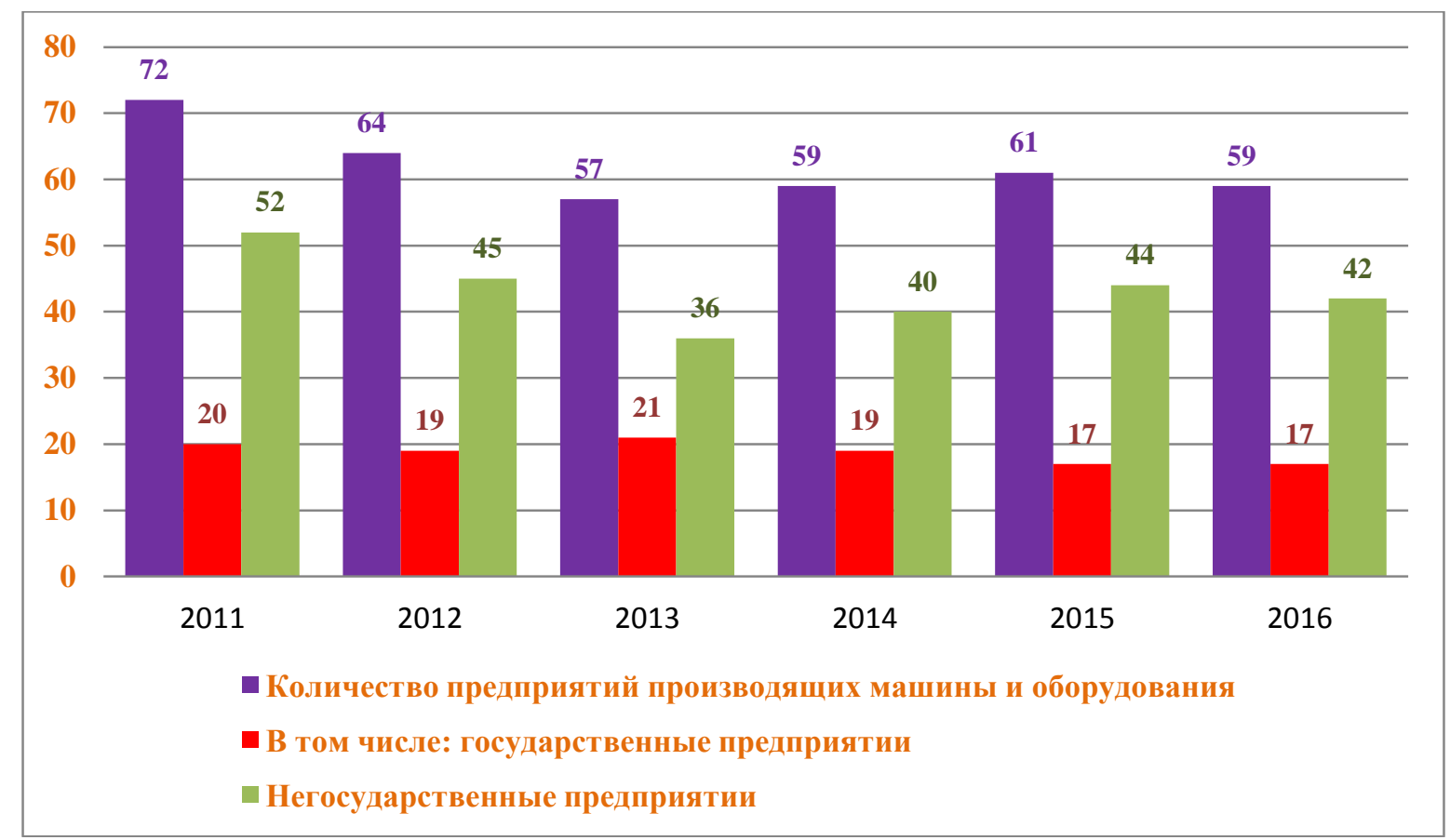

Рисунок 2 - Количествно предприятий, производящих машины и оборудование в Азербайджане, 2011-2016 годы (подготовлено автором на основе материалов Государственного Статистического Комитета Азербайджанской Республики, http://www.azstat.org).

В 2011-2016 годы количество предприятий, производящих машины и оборудование в Азербайджане уменьшилось с 72 до 59. Более того, к сожалению, больше всего уменьшилось число негосударственных предприятий, с 52 до 42. Эти факты показывают, что имеется необходимость проводить серьезные изменения в структуре и системе управления всего машиностроительного комплекса страны в ближайшей перспективе и тем самым обеспечить рыночное развитие в данной отрасли с привлечением иностранных инвестиций, зарубежных машиностроительных компании, созданием машиностроительных кластеров и других более эффективных механизмов по развитию данной отрасли [12].

А так можно отметить совместную деятельность Гянджинского Автомобильного Завода с профильными предприятиями Республики Беларусь сфере производства тракторов (Рисунок 3).

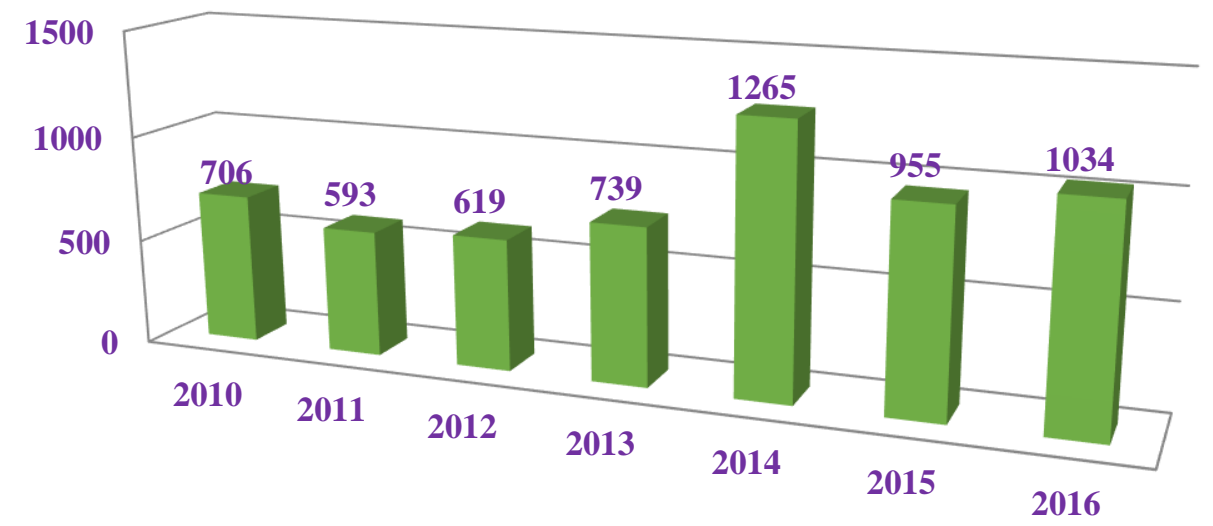

Рисунок 3 - Динамика производства тракторов в Азербайджане, 2010-2016 годы (подготовлено автором на основе материалов Государственного Статистического Комитета Азербайджанской Республики, http://www.azstat.org).

ISPC Innovations in science, 


\begin{tabular}{|c|c|c|c|c|c|c|}
\hline Impact Factor: & $\begin{array}{l}\text { ISRA (India) } \\
\text { ISI (Dubai, UAF } \\
\text { GIF (Australia) } \\
\text { JIF }\end{array}$ & $\begin{array}{l}=1.344 \\
=0.829 \\
=0.564 \\
=1.500\end{array}$ & $\begin{array}{l}\text { SIS (USA) } \\
\text { PИНЦ (Russia) } \\
\text { ESJI (KZ) } \\
\text { SJIF (Morocco) }\end{array}$ & $\begin{array}{l}=\mathbf{0 . 9 1 2} \\
=\mathbf{0 . 2 0 7} \\
=\mathbf{3 . 8 6 0} \\
=\mathbf{2 . 0 3 1}\end{array}$ & $\begin{array}{l}\text { ICV (Poland) } \\
\text { PIF (India) } \\
\text { IBI (India) }\end{array}$ & $\begin{array}{l}=6.630 \\
=1.940 \\
=4.260\end{array}$ \\
\hline
\end{tabular}

На Рисунке 4 дано количество предприятий производящих автомобили и прицепы в Азербайджане за 2011-2016 годы.

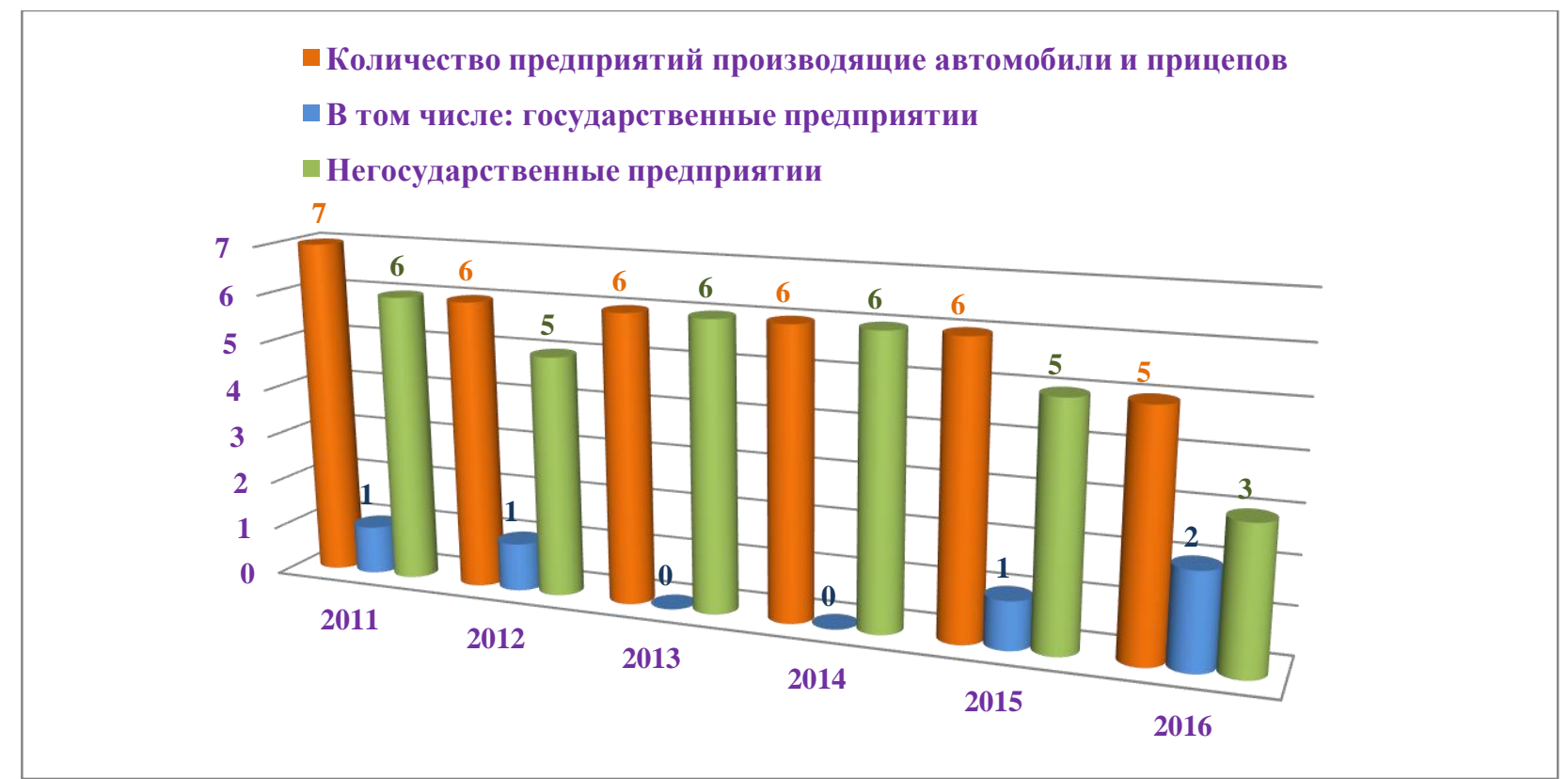

Рисунок 4 - Количество предприятий, производящих автомобили и прицепы в Азербайджане, 20112016 годы (подготовлено автором на основе материалов Государственного Статистического Комитета Азербайджанской Республики, http://www.azstat.org).

За 2011 и 2016 годы число негосударственные предприятий, производящих автомобили и прицепы не выдержав конкуренции, снизилось от 6 до 3. Однако сформировались новые производственные мощности по производству автомобилей с участием аналогичных предприятий России, Беларуси и Ирана [13]. В Гянджинском и Нахчиванском автомобильных заводах производятся легковые и грузовые автомобили, динамика которых дана на Рисунке 5.

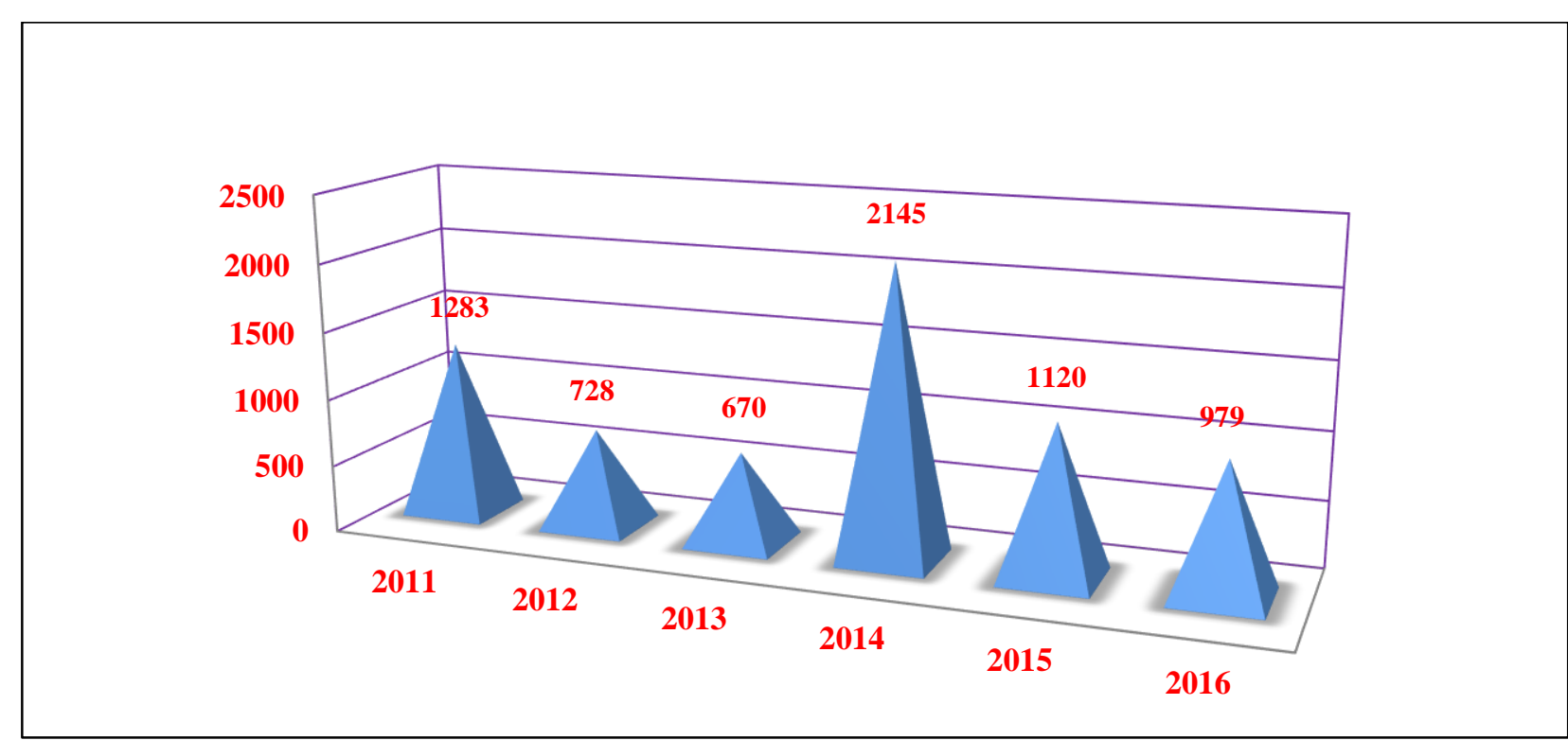

Рисунок 5 - Динамика производства легковых и грузовых автомобилей в Азербайджане, единицы, 2011-2016 годы (подготовлено автором на основе материалов Государственного Статистического Комитета Азербайджанской Республики, http://www.azstat.org).

ISPC Innovations in science, 


\begin{tabular}{|c|c|c|c|c|c|c|}
\hline Impact Factor: & $\begin{array}{l}\text { ISRA (India) } \\
\text { ISI (Dubai, UAE } \\
\text { GIF (Australia) } \\
\text { JIF }\end{array}$ & $\begin{array}{l}=1.344 \\
=0.829 \\
=0.564 \\
=1.500\end{array}$ & $\begin{array}{l}\text { SIS (USA) } \\
\text { PИНЦ (Russia) } \\
\text { ESJI (KZ) } \\
\text { SJIF (Morocco) }\end{array}$ & $\begin{array}{l}=0.912 \\
=0.207 \\
=\mathbf{3 . 8 6 0} \\
=\mathbf{2 . 0 3 1}\end{array}$ & $\begin{array}{l}\text { ICV (Poland) } \\
\text { PIF (India) } \\
\text { IBI (India) }\end{array}$ & $\begin{array}{l}=6.630 \\
=1.940 \\
=4.260\end{array}$ \\
\hline
\end{tabular}

\section{Conclusion}

Как видно за 2011 и 2016 годы особого роста производства легковых и грузовых автомобилей в Азербайджане не наблюдалось, и эти факторы обуславливают разработку и осуществление более действенных мер по интенсификации развития машиностроительного комплекса страны. Стратегическая цель и задачи машиностроительного комплекса страны определены на краткосрочную и долгосрочную перспективу в стратегической карте по развитию тяжелой промышленности и машиностроения в Азербайджанской Республике, которая утверждена указом Президента Азербайджанской Республики от 6 декабря 2016 года [14]. С осуществлением стратегической цели ожидается серьезное преобразование системы управления и структуры выпуска продукции машиностроительных предприятий и в целом машиностроительного комплекса в Азербайджане.

\section{References:}

1. (2016) Strategicheskiye dorozhnyye karty po perspektivnomu razvitiyu natsional'noy ekonomiki Azerbaydzhanskoy Respubliki. Utverzhdeno Ukazom Prezidenta Azerbaydzhanskoy Respubliki ot 6 dekabrya 2016 goda.

2. (2017) Mashinostroyeniye. Available: http://azerbaijans.com/content_724_ru.html. (Accessed: 10.09.2017).

3. (2017) OAO "AZNEFTEKHIMMASH". Available:

http://www.azneftkimyamash.com/aznkm_hom e_rus.htm. (Accessed: 10.09.2017).

4. (2014) O mashinostroitel'noy promyshlennosti Azerbaydzhana. Promyshlennyy portal Azerbaydzhana. Baku, 2014.- 14 p. Available: www.senaye.gov.az. (Accessed: 10.09.2017).

5. (2015) Spravka po mashinostroitel'noy promyshlennosti. Ministerstvo ekonomiki i promyshlennosti Azerbaydzhanskoy Respubliki Baku, 2015.- 13 p. Available: www.senaye.gov.az. (Accessed: 10.09.2017).

6. (2017) Mashinostroyeniye v Azerbaydzhane. Available: http://worldofscience.ru/geografijamira/21-geografija-azerbajdzhana/514mashinostroenie-v-azerbajdzhane.html. (Accessed: 10.09.2017).

7. Eyvazov F.D. (2011) Analiz sovremennogo sostoyaniya razvitiya mashinostroitel'noy promyshlennosti Azerbaydzhana // Rossiyskoye predprinimatel'stvo. - 2011. - Tom 12. - № 7. p. 90-94.
8. Efendiyev S.G. (2014) Otsenka roli mashinostroitel'nykh predpriyatiy v ekonomicheskom razvitii Azerbaydzhana// Mezhdunarodnyy tekhniko-ekonomicheskiy zhurnal. Izdatel'stvo: uchebno-metodicheskiy tsentr "Triada" (Moskva). Nomer: 3- god: 2014. -p. 49-53.

9. (2017) Azerbaydzhan v tsifrakh. Baku, 2017.$286 \mathrm{p}$.

10. (2017) Promyshlennost' Azerbaydzhana. Statisticheskoye izdaniye. Baku, 2017.- 344 p.

11. (2014) Gosudarstvennaya programma po razvitiyu promyshlennosti v Azerbaydzhanskoy Respublike (2015-2020 gody), 26 dekabrya 2014 god. Available: http://www.president.az. (Accessed: 10.09.2017).

12. Aliyev SH.T. (2015) Faktory, obuslavlivayushchiye primeneniya promyshlennykh klasterov v uskorenii razvitiya natsional'noy ekonomiki // Zhurnal Audit, № 4, 2015, p.73-79.

13. (2017) Avtomobil'naya promyshlennost' Azerbaydzhana perezhivayet period rastsveta. 22 aprelya 2015 g. Available: http://www.mashportal.ru/machinery world38722.aspx. (Accessed: 10.09.2017).

14. (2016) Strategicheskaya karta po razvitiyu tyazheloy promyshlennosti i mashinostroyeniya v Azerbaydzhanskoy Respublike. Utverzhden ukazom Prezidenta Azerbaydzhanskoy Respubliki ot 6 dekabrya 2016 goda. 